\title{
Growth of Tilia cordata Mill. in Urban Forests
}

\author{
Maria Martynova ${ }^{1 *}$, Rida Sultanova $^{1}$, Georgiy Odintsov $^{1}$, Regina Sazgutdinova $^{1}$, Elvira Khanova ${ }^{1}$
}

(1) Bashkir State Agrarian University, Federal State Budgetary Educational Establishment of Higher Education, Department of Forestry and Landscape Design, 50th anniversary of October 34, RU-450001 Ufa, Russian Federation

* Correspondence: e-mail: martynovam90@bk.ru

\begin{abstract}
Citation: Martynova M, Sultanova R, Odintsov G, Sazgutdinova R, Khanova E, 2020. Growth of Tilia cordata Mill. in Urban Forests. South-east Eur for 11(1): 51-59. https://doi.org/10.15177/seefor.20-04 Received: 15 Oct 2019; Revised: 5 Feb 2020; Accepted: 1 Mar 2020; Published online: 17 May 2020
\end{abstract}

\begin{abstract}
Tilia cordata Mill. is considered to be the main tree species resistant to urban conditions and it is widely used in the greening of cities. The aim of the study is to assess the patterns of growth and development of small-leaved linden plantations in the urban environment. The research is based on the method of sample areas where continuous enumeration survey has been carried out. The study of urban greening objects was conducted using the methods of landscape assessment and complete enumeration of trees in alley plantings. It was found that Tilia cordata Mill. grows in all districts and zones of the city of Ufa, occupying $34.4 \%$ of green areas. During this research it was found that artificially created alley plantings of Tilia cordata Mill. are more well-kept and have well-developed crowns which create a tree shade sometimes 8-10 meters wide (the average crown projection being $7 \mathrm{~m}$ ). Since alley plantings have repeatedly been pruned, trees in this area are characterized by a large increase in diameter and strong height growth stagnation. Thus, when studying linden plantings of the same age, a sharp difference in the size and shape of trees was observed.
\end{abstract}

Keywords: Tilia cordata Mill.; urban forests; soil; planting; silvicultural and taxation indicators

\section{INTRODUCTION}

Today, large cities are artificial systems created and managed by man (Strohbach and HaasE 2012, Zölch et al. 2017). Ecological balance support, as well as the search for the improvement of the technogenic habitat, is an urgent problem. Not every living plant, whether shrubs or tree plantations, can adapt to the urban environment and survive in it, not to mention their positive impact on the environment (Moser et al. 2017, Sultanova et al. 2018, Rahman et al. 2019), which is further considered in the 'Results and Discussion' section.

For several decades, scientists have been actively studying the role of trees and shrubs in improving the quality of man-made and urban habitats, as well as their impact on the environment. Long-term studies have revealed an important positive environmental role of green plantings in the regulation of atmospheric air, city micro-climate, and in the protection of the urban environment from negative anthropogenic factors (Konashova et al. 2018, Sultanova et al. 2018, Rahman et al. 2019, Urošević et al. 2019). Tree plantations are a powerful natural factor in countering negative environmental effects of urbanization and manmade pollution (Glibovitskaia 2014).
Ecological, silvicultural and social significance of green plantings cannot be overestimated (Kabisch and Haase 2014, Konashova et al. 2018, Sultanova et al. 2018). Green plantings affect the city micro-climate, reducing summer temperature by $4-6^{\circ} \mathrm{C}$ (Rahman et al. 2017, 2019). Having large transpiring ability, they transpire moisture 20 times more than the area they occupy, significantly increasing air humidity (Margaritis and Kang 2017, Zölch et al. 2017). In some cases, tree species in urban conditions have a greater influence on radiation than on changes in temperature and humidity (Takács et al. 2016). Tree plantations significantly reduce the speed of atmospheric circulation (Strohbach and Haase 2012). Their leaves have high resonance ability, reducing the noise level by 10-15 dB (Margaritis and Kang 2017). Green plantings play an important role in the purification of urban air from dust: dust content of air in urban parks in winter is $37 \%$ and in spring and summer $42 \%$ lower than in open spaces (Strohbach and Haase 2012, Margaritis and Kang 2017). The aspects of the social functions of plantations are as follows: provision of recreational services (Konashova et al. 2018, Sultanova et al. 2018), improvement of physical, spiritual and moral conditions of humans (Xu et al. 2018), and the creation of 
population vacation destinations (Bijker and Sijtsma 2017).

The urban environment is usually characterized by various types of stress, creating problems for tree species (Moser et al. 2017, Moser-Reischl et al. 2019). Atmospheric pollution has both direct and indirect impact on the formation of the chemical composition of assimilating plant organs through the soil, resulting in failure to supply plants with nutrients. Plant damage begins with the penetration of toxicants into the leaf and their impact on biochemical cellular processes. From this point of view, the research of assimilation organs, which absorb pollutants as a result of intensive gas exchange, is of scientific interest (Ziiatdinova et al. 2012, Moser et al. 2015).

In this context, linden is one of the main tree species that are resistant to urban conditions and are widely used in different climatic zones of Russia for the greening of cities. Plants of this species are used as street plantings in public gardens, cities and forest parks (Chopikashvili et al. 2014).

Almost all linden trees have the advantages such as compact leafy crown; they are shade-tolerant, easy-going about soil conditions, resistant to wind, non-allergenic, and quite highly resistant to aggressive urban environment characterized by smoke, mud, dust, and air pollution (Teplaya 2013 Moser et al. 2015, Rahman et al. 2017, Sultanova et al. 2018). In addition, when transplanted even in an adult state, Tilia cordata Mill. successfully adapts to growing conditions. It is not much exposed to diseases and can resist pests. Moreover, linden has won its great popularity thanks to its decorative features which it possesses throughout the year (Zölch et al. 2017, Sultanova et al. 2018, Zhang et al. 2019).

Natural areas of Tilia cordata are Europe and adjacent areas of Asia (Moser et al. 2017, Konashova et al. 2018, Urošević et al. 2019). It is widespread in the middle and southern forest zone and in the European forest-steppe zone of Russia. Some area fragments of this species are represented in Western Siberia (e.g. linden forest outliers in Kuznetsk Alatau Reserve and in other areas). Linden trees form pure forests (Tilientums), but they also grow as mixed plantings in broad-leaved and mixed forests where the basis of the stand are other species, such as English oak, for example. Linden trees often grow in grove forest understory and in mixed coniferous broad-leaved forests (Glibovitskaia 2014).

These trees are widely grown as urban plantings along the streets, in parks and squares, as well as a type of hedgerow. They respond well to crown cutting. They grow in Moscow and other cities of the European part of Russia. Large-leaved linden (Tilia platyphyllos) which originates from Central Europe is also found in plantings together with Tilia cordata. It differs from the domestic linden and has larger leaves and flowers, and its flowering time begins earlier (about 2 weeks earlier) (Chopikashvili et al. 2014, Sultanova et al. 2018).

Small-leaved linden (Tilia cordata Mill.) can be used as a bioindicator for bioindication studies. The prospect of its use to assess environmental health under anthropogenic load is quite justified (Chopikashvili et al. 2014, Kabisch et al. 2016, Konashova et al. 2018, Sultanova et al. 2018). Leaves of linden trees in urban environments accumulate nitrogen dioxide, sulfur dioxide, heavy metals, salts and dust. As a result of leaf fall, all harmful substances get into the soil, thereby salting it. However, due to a large amount of calcium in the leaves of linden trees (in conditions of the city of Ufa ranging from 22.5 to $37.5 \mathrm{mg}$.eq. $100 \mathrm{~g}$. soil $^{-1}$ ), leaf fall during decomposition reduces soil acidity and enriches it with humus.

Small-leaved linden is rather widespread in the Republic of Bashkortostan and makes more than $30 \%$ of lime woods of Russia. However, despite natural occurrence of small-leaved linden, its biological and environmental characteristics under man-made conditions have been recently studied quite poorly. At the same time, there is some fragmentary information on the impact of polluted environment on the above-ground organs of plants, but there is no such information on root system formation under the same conditions.

The aim of the study is to assess the patterns of growth and development of small-leaved linden plantations in the urban environment on the example of the city of Ufa in the Republic of Bashkortostan.

\section{MATERIALS AND METHODS}

\section{Study Area}

The research was carried out in the city of Ufa, the Republic of Bashkortostan, on the areas where the plantings of pure Tilia cordata Mill. grow on the territory of the foreststeppe region of the European part of Russia (Figure 1).

Long-term experimental studies (2007-2018) of silvicultural and taxation indicators of natural and artificial plantations of small-leaved linden were carried out on permanent study areas (PSA), and laid out using wellknown forest estimation methods. Study areas were laid out according to regulatory requirements in compliance with the "Forest management study areas" All-Union Standard 56-60-83. Plantation establishment method" (Gost 2018). Taxation of the selected sample areas was performed by ocular estimation method. The average taxonomic indicators were determined in accordance with Forest Management Instructions (Forest Management Instruction 2018). In alleys with the area of 0.96 ha the sample coverage of linden trees was 680 trunks, out of which 612 trunks were of Tilia cordata Mill. (0.2 ha). The methods of landscape assessment and plantation trees' complete enumeration were applied to study urban greening objects. The state of the trees was determined in conjunction with their biomorphological features such as the crown color and its density; the color and damage of leaves; the presence of pests; relative shoots and wood growth; leaves' size; the presence of dry branches; bark and phloem state. Height and crown length were defined using a hypsometer. The crown projected diameter was determined by sighting crown projection in the direction of North-South and West-East, and by measuring the distance between the points of sighting.

In accordance with the requirements of the State All-Union Standard (State All-Union Standard 12536 of 2014) aggregation analysis of soils was made in the forest research experimental production laboratory (FSREPL) (Gost 2016). Soil subsample was selected by applying the double quartering method. Then the soil was weighed and bolted through a standard sieve. From the sample mass quantity $100 \%$ of the mass fractions were calculated. The calculations helped to establish the content of units of different size in 


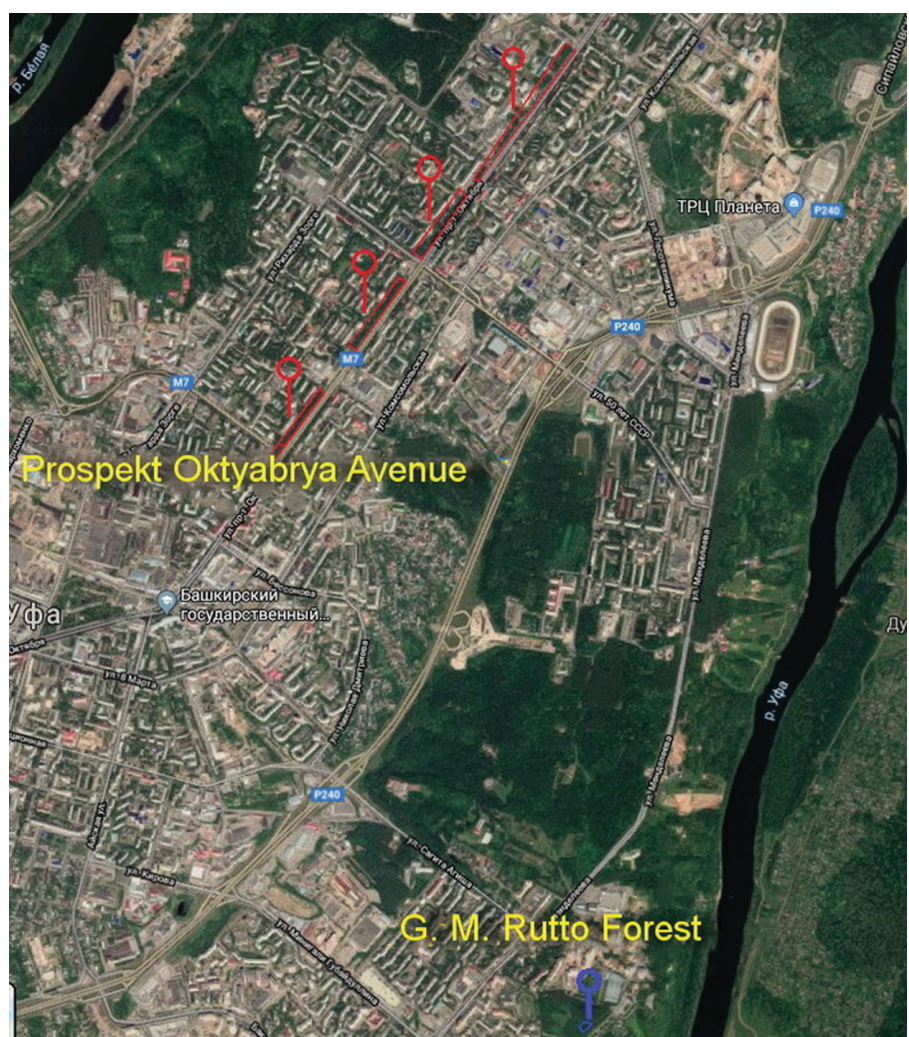

Figure 1. Research objects: The G. M. Rutto Park; alley alongside Prospect Oktyabrya Avenue.

the soil. The results were interpreted using the classification of mechanical elements. The amount of P2O5 in milligrams per $100 \mathrm{~g}$ of dry soil was determined in accordance with the calibration curve.

\section{Statistical Analysis}

The statistical and mathematical data processing was conducted with the use of Statistica 12 application program package and Microsoft Excel. The estimate reliability of potential correlations was determined with respect to the student's criterion $(t \leq 0.05)$. The equation significance was estimated by the correlation coefficient $(r, \%)$. The obtained values were processed by standard variation statistics methods. Dependencies were found between: 1 ) diameters and heights of linden trunks; 2) diameter and length of the crown.

\section{RESULTS AND DISCUSSION}

The analysis of urban plantations in Ufa showed that they currently occupy the area of 227.4 ha. Soft-wooded broadleaved species predominate and account for $63.3 \%$ of the forest area. Hard-wooded broadleaved species make up $27.3 \%$ and coniferous species make up $4.2 \%$. Other species and shrubs occupy $5.2 \%$ of the area (Figure 2 ).

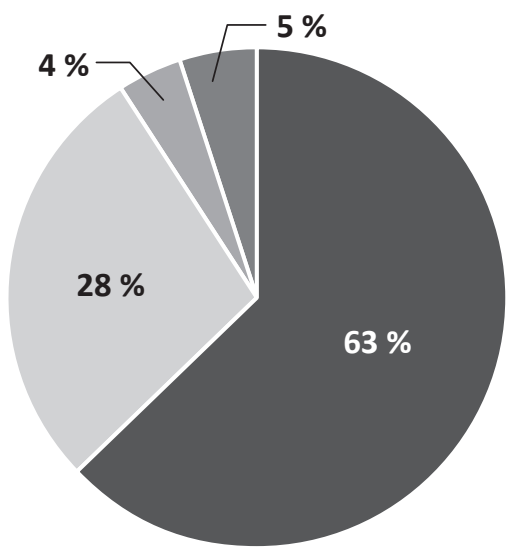

Soft-wooded broadleaved tree plantation

Hard-wooded broadleaved tree plantation

Conifers

Others

Figure 2. Grouping of urban green plantations in accordance with tree species they belong to. 
Soft-wooded broadleaved tree plantations are represented by the following species: linden $-54.4 \%$, black alder $-17.8 \%$, birch $-8.1 \%$, sedge $-7.1 \%$, black poplar $6.0 \%$, poplar $-3.6 \%$, aspen $-2.6 \%$, gray alder $-0.4 \%$. Low oak trees predominate in hard-wooded broadleaved plantations $(42.0 \%)$, elm family trees come second $(39.5 \%)$, ash trees make $9.8 \%$, maple trees $5.3 \%$ and high oaks $3.4 \%$. Pine dominates among conifers making $51.3 \%$, spruce $33.7 \%$, larch $14.7 \%$ and cedar $0.3 \%$ (Figure 3 ).

Silvicultural and taxation assessment of urban plantations showed uneven-aged grouping of tree species: $5.4 \%$ are small pole, $42.1 \%$ are middle-aged trees, $20.1 \%$ are stands approaching maturity, and $32.4 \%$ are mature and overmature trees. The share of close stands accounts for $15.4 \%$, mediumstocked make $46 \%$, and the number of low-stocked amounts to $38.6 \%$. The average stocking is 0.6 . In terms of productivity, plantations are classified as middle class bonitet (II, 6). Urban forests are characterized by the predominance of nettle and meadowsweet trees (57\%). Mixed herb forests make 32.6\%, sedge and Sphagnum forests amount to $8.8 \%$, and grass forests account for $1.6 \%$.

Tilia cordata Mill. is a favorite tree for urban landscaping. Ufa is not an exception. This tree species is also widely used in landscaping of large cities in Russia such as Moscow, Voronezh, Tula, and Ekaterinburg. Small-leaved linden possesses high aesthetic qualities such as shade tolerance and frost resistance. It is able to stand temperature changes against the background of moisture lack in the soil (Rahman et al. 2019).
However, it responds well to artificial crown formation.

Tilia cordata Mill. is grown in all districts and zones of the city of Ufa, occupying $34.4 \%$ of its green areas. To study the dynamics of woody vegetation development in urban conditions, long-term observation on permanent sample areas (PSA) is required. Small-leaved linden trees' complete enumeration was conducted during the research on PSA. Taxational characters of 1303 trunks were measured.

The studied areas of small-leaved linden plantations differ from each other in structure, soil and hydrological conditions, light regime, intraspecific competition, recreational loading and in other indicators. The studied plantations of Tilia cordata Mill. are included in the group of urban green areas of general purpose.

It should be noted that the quantity and morphology of urban woody species are still poorly studied, especially with regard to changes caused by the urban environment. However, forest valuation indicators and tree functions are strongly intertwined. Thus, Rahman et al. (2017) analyzed the growth and development of Tilia cordata Mill. growing in Munich (Germany) and found out that growing conditions influence significantly the ratio of tree parameters such as height and diameter.

During this research, the dynamics of growth and development of small-leaved linden (Table 1) growing either in natural conditions (G. M. Rutto Forest Park) or in artificially created groves (e.g. tree alley alongside Prospekt Oktyabrya Avenue) were studied.

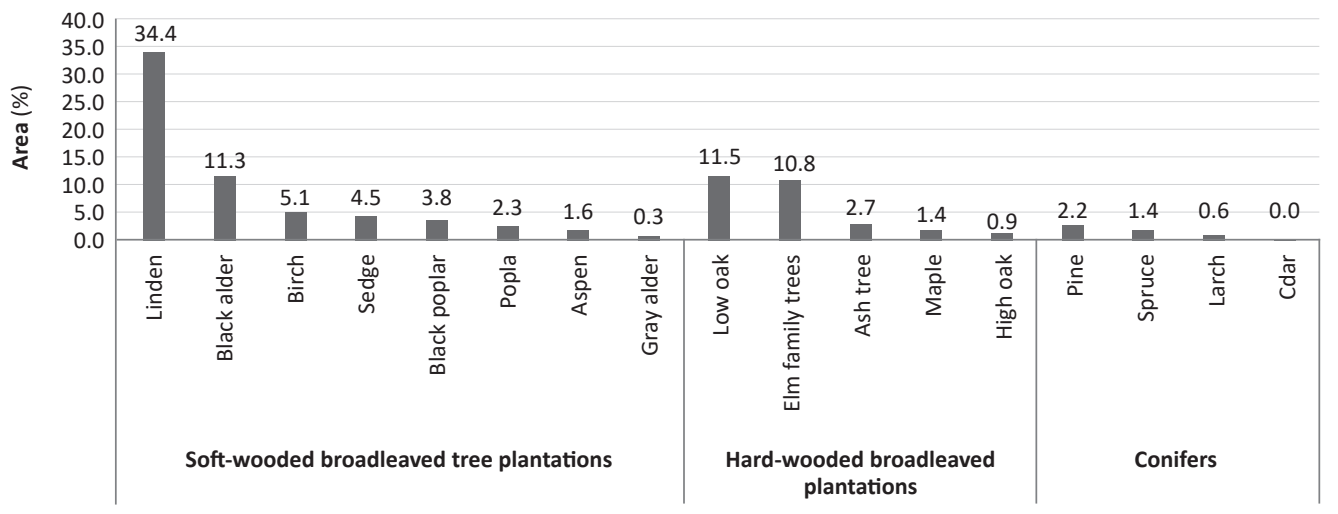

Figure 3. Species representation of urban plantations.

Table 1. Average silvicultural and taxation indicators of sample areas grouped by year.

\begin{tabular}{|c|c|c|c|c|c|}
\hline $\begin{array}{c}\text { Year of } \\
\text { measurement }\end{array}$ & $\begin{array}{l}\text { Quantity } \\
\text { (pcs) }\end{array}$ & $\begin{array}{l}\text { Height } \\
(\mathrm{m})\end{array}$ & $\begin{array}{l}\text { Diameter } \\
(\mathrm{cm})\end{array}$ & $\begin{array}{c}\text { Crown length } \\
(\mathrm{m})\end{array}$ & $\begin{array}{c}\text { Crown diameter } \\
(\mathrm{m})\end{array}$ \\
\hline \multicolumn{6}{|c|}{ Comparison of average growth and development indicators of trees growing in the G. M. Rutto Park } \\
\hline 2007 & 626 & $18.2 \pm 0.03$ & $18.4 \pm 0.03$ & $8.5 \pm 0.01$ & $6 \pm 0.01$ \\
\hline 2018 & 623 & $20.8 \pm 0.03$ & $19.7 \pm 0.03$ & $3.67 \pm 0.01$ & $9.4 \pm 0.01$ \\
\hline \multicolumn{6}{|c|}{ Comparison of average growth and development indicators of trees growing on the alley alongside Prospekt Oktyabrya Avenue } \\
\hline 2007 & 727 & $13.1 \pm 0.04$ & $30.1 \pm 0.02$ & $5 \pm 0.01$ & $9 \pm 0.01$ \\
\hline 2018 & 688 & $14 \pm 0.04$ & $34.1 \pm 0.02$ & $7.5 \pm 0.01$ & $10.2 \pm 0.01$ \\
\hline
\end{tabular}


The average diameter of trees growing in the G. M. Rutto Park is $19.7 \pm 0.03 \mathrm{~cm}$, and their average height is $20.8 \pm 0.03$ $\mathrm{m}$. The tables contain data on trees' distribution according to bonitet classes they belong to. Based on the tables date it can be assumed that plantings are of bonitet class II. Taking into account the data of Matveev-Motin tables for linden high forest growth, it can be seen that park tree parameters differ in minimum average values from the parameters of naturally growing plants. However, there is a fallback in diameter due to high forest density (1.0).

The alley alongside Prospekt Oktyabrya Avenue is managed better and differs in strongly developed crowns creating a shadow which is sometimes $8-10 \mathrm{~m}$ wide (the average crown projection is $7 \mathrm{~m}$ ). Since alley plantings have repeatedly been pruned, trees in this area are characterized by a large increase in diameter and strong height growth stagnation. The average diameter of a plant is $34.1 \pm 0.02$ $\mathrm{cm}$, and its average height is $14 \pm 0.04 \mathrm{~m}$. Diameter growth indicators of Tilia cordata Mill. growing in the conditions of the city of Munich (Germany) range from $11 \mathrm{~cm}$ to $102.2 \mathrm{~cm}$. The average annual increase in diameter is $0.39-0.40 \mathrm{~cm} \cdot \mathrm{year}^{-1}$ (Moser et al. 2015).

The average height of alley trees alongside Prospekt Oktyabrya Avenue for 11 years increased by $0.6 \pm 0.01 \mathrm{~m}$ $\left(0.05 \pm 0.01 \mathrm{~m} \cdot\right.$ year $\left.^{-1}\right)$, and the average diameter increased by $4 \pm 0.01 \mathrm{~cm}\left(0.36 \pm 0.01 \mathrm{~m} \cdot\right.$ year $\left.^{-1}\right)$. The increase of average diameter of trees growing in the G. M. Rutto Park for 11 years was $1.3 \pm 0.01 \mathrm{~cm}\left(0.12 \pm 0.01 \mathrm{~m} \cdot\right.$ year $\left.^{-1}\right)$, and their height increased by $2.6 \pm 0.01 \mathrm{~m}\left(0.26 \pm 0.01 \mathrm{~m} \cdot \mathrm{year}^{-1}\right)$. The data prove that conditions in which trees in the park grow and develop are closer to natural habitat than those in the alley. Diameter increase in alley trees is higher due to tree pruning and because of lower tree competition, as the distance between individual trees is bigger.

Figure 4 shows the curve of dependence of trunk diameter of small-leaved linden growing in the alley on its height. The variability is approximated by the equation $y=-0.004$ $x^{2}+0.3999 x+5.1391$, when the correlation coefficient $r=0.3310$. Regression equation has the form $y=0.1281 x+9.6192$.

The variability of crown diameters and crown length of

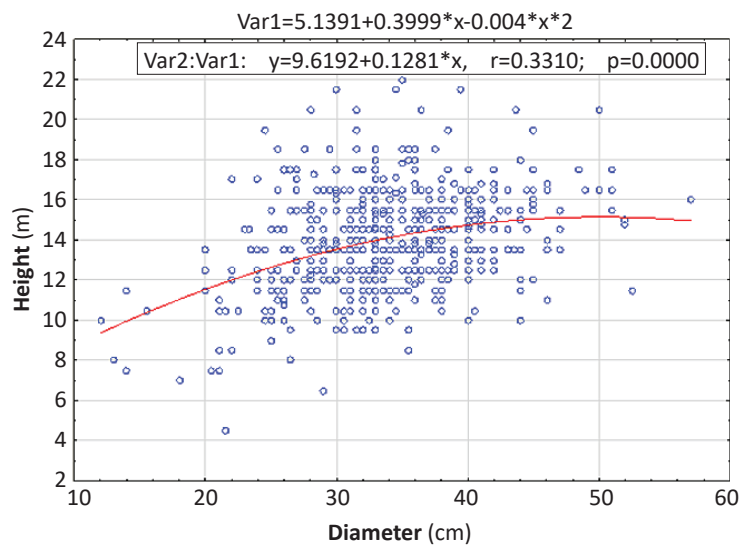

Figure 4. Dependence of the diameter of small-leaved linden trunks on height. small-leaved linden trunks is characterized by the equation $y=0.0284 x^{2}+0.0792 x+7.9006$, when the value of the correlation coefficient $r=0.4189$. Regression equation has the form $y=0.1281 x+9.6192$.

Weak and insignificant correlation of trunk diameter, crown diameter and height of trees growing in the Rutto Forest Park can be explained by the presence of a small sampling size.

On the basis of measurements, the analysis of linden silvicultural indicators was made. Sampling helped to make quantitative and percentage diameter distribution table (Figure 5, 6).

The number of trees growing in the park (Figure 6) whose diameter is thinner than the average diameter makes $36.6 \%$ of their total number. The trees with thicker diameter amount to $63.4 \%$ (according to A.V. Tiurin they make $57.25 \%$ and $42.5 \%$

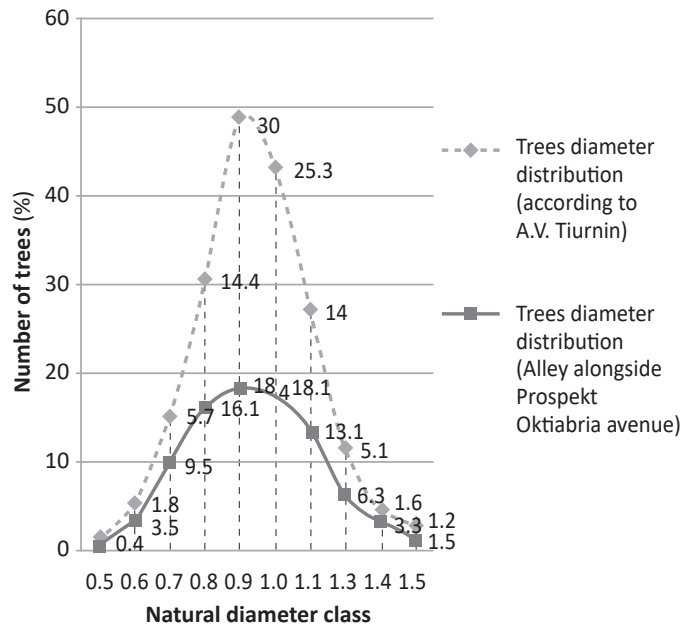

Figure 5. Trees' diameter distribution table (Alley alongside Prospekt Oktyabrya Avenue).

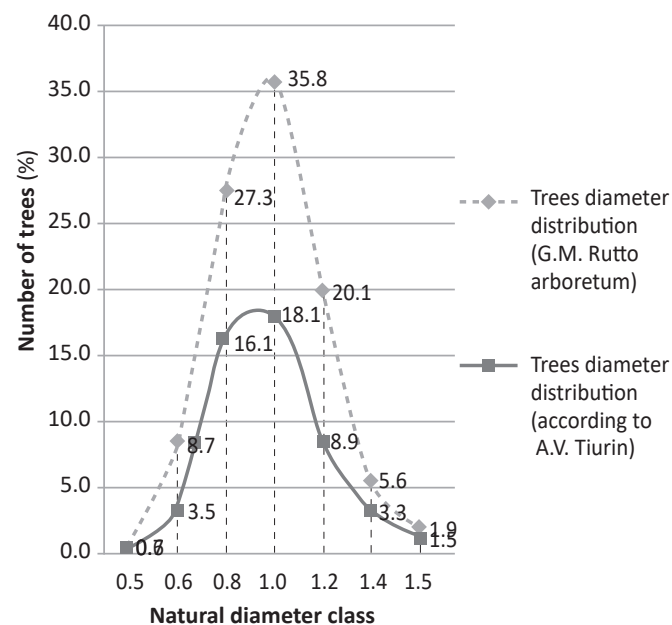

Figure 6. Stand trees' diameter distribution table (G. M. Rutto arboretum). 
respectively). This results in low plantation thinning and mortality of weakened trees provoked by their mechanical damage.

Trees of central diameter class $(28,32,36,40)$ growing in the alley amount to $83.7 \%$ of the total number of trees. Maximum number of normal stands are of 24,28 , and 32 diameter classes making up $64.7 \%$ of the total number of trunks. The series of trees' diameter distribution is characterized by an asymmetric single-humped curve.

Currently 680 linden trees grow in the alley, but according to research data in 2007724.44 linden trees were cut down due to the construction of new bus stops, pedestrian crossings and the clearing of dead trees. The average taxation indicators of trees growing in the alley and in the forest park increased on the whole.

Plants growing in the city require all necessary nutrients for their growth and development, which can be provided by the soil as their primary supplier. However, in the urban environment soils accumulate not only various forms of waste, but also pollutants that can have a negative impact on the rhizosphere, which kills trees (Glibovitskaia 2014, Sultanova et al. 2018).

During the research soil pits were made. Soil structural composition and its characteristics were obtained.

A0-A1 soil layer in the linden forest in G. M. Rutto Park contains only $33.17 \%-37.30 \%$ of small granular structure aggregates. This suggests that the soils there are waterlogged and their water and heat balance is broken (Field studies of the soil 1984 ,Nature protection 2008, Ziiatdinova et al. 2012, Mudarisov et al. 2019). There is also excessive compaction provoked by people's recreational activities.

This indicator in the topsoil of the alley made up 2.453.3. In the park topsoil it was only 0.5-0.6. The alley soil structure rating was 5 times higher in comparison with the same indicator in the park soils. There are some factors that suppress small-leaved linden trees, but despite them a positive increase in trees' diameter can be observed, which amounts to $4.4 \pm 0.01 \mathrm{~cm}$ for an eleven-year period $\left(0.4 \pm 0.01 \mathrm{~m} \cdot\right.$ year $\left.^{-1}\right)$.

Top soil layers (A0-A1-A2-AB soil horizons) of the analyzed sample areas are characterized mainly by neutral and weak acid medium ( $\mathrm{pH}$ medium=Of 5.84-of $6.98 \mathrm{U}$ ). In the lower horizons the soil becomes more acidic $(\mathrm{pH}$ medium=4.17-of 7.02 U). Though $\mathrm{pH}$ medium indicators in the alley soils are within the limits characterizing a neutral medium, in some layers they provide alkaline reaction, and the indicators are then on the border. Medium reactions that take place in the soils of the forest park indicate that the soil there is more acidic.

Park soils are more saturated with calcium cations (23.8-31.3 mg.eq·100g.soil $\left.{ }^{-1}\right)$ and magnesium (4.8-5.5 mg.eq.100g.soil ${ }^{-1}$ ) than those in the alley, in which the content of calcium is $22.5-26.3 \mathrm{mg} . \mathrm{eq} \cdot 100 \mathrm{~g} . \mathrm{soil}^{-1}$, while magnesium content is $3.5-6.5 \mathrm{mg}$.eq $\cdot 100 \mathrm{~g} \cdot \mathrm{soil}^{-1}$. Calcium prevails in all cases.

Soil saturation with ammonium (NH4) in the sample areas throughout the soil profile is to some extent similarly low. The content of nitrate (NO3) in the alley soils is slightly higher than in the forest park, but in both cases its provision rate is low. Throughout the soil profile in the alley, the indicators range from $1.35-28.2 \mathrm{mg} . \mathrm{eq} \cdot 100 \mathrm{~g}^{-1}$ (NO3), 3.5-15.1 mg.eq $100 \mathrm{~g}^{-1}(\mathrm{NH} 4)$ and within 0.96-11.6 mg.eq $100 \mathrm{~g}^{-1}$ (NO3), $1.5-19 \mathrm{mg} . \mathrm{eq} \cdot 100 \mathrm{~g}^{-1}(\mathrm{NH} 4)$.

The analysis of the soils in the areas where linden plantations are grown showed that there are large silt particles in the soil mantle. So, soils in that areas are dark gray forest soils. Such soils are characterized by a small quantity of sand particles, and thus can be named heavy loamy clay-silt soils. This process does not greatly affect the development of the root system of trees and plantations growing in such soils. Based on their exploitable use for linden tree planting, it can be concluded that these areas have proper soil conditions.

At the same time, the soil under small-leaved linden canopy accumulates various substances. Studies conducted in Louisville (USA) showed that the movement of salts, heavy metals and other elements in the soil are of great importance in determining the state of urban plantations (Trammell et al. 2011). As for the city of Ufa, soil root occupation here increased as well as the proportion of semiskeletal and skeletal roots. During the growing period there was a migration of lead, copper and cobalt from the leaves to the roots. In Germany, the study of soils in urban areas where Tilia cordata Mill. grows revealed that this tree species contributes to the soil humidity decrease and to the soil temperature rise (Moser et al. 2015, 2017, Rahman et al. 2017, Moser-Reischl et al. 2019), increasing at the same time the latent current (Moser et al. 2017). This research has shown that the soils on which Tilia cordata Mill. grows are waterlogged and that their air-heat balance is disturbed.

The study of the structural response of 52 Tilia cordata Mill. trees conducted in Munich (Germany) showed that growing conditions had a significant impact on the heightdiameter ratio in the presence of pronounced crown asymmetry (Bayer et al. 2018). Moser et al. (2015, 2017) and Moser-Reischl et al. (2019) in their studies analyzed the growth of Tilia cordata Mill. in urban conditions and revealed a close relationship $\left(r^{2}>0.7\right)$ between crown diameter, trunk diameter, crown projection area and height of Tilia cordata Mill. The results of our studies have shown that Tilia cordata Mill. growing in parks has a better developed crown than in street alleys. However, it has to be noted that in the park growing and development conditions for trees are closer to the natural habitat, rather than the conditions in the alley. Diameter increase in alley trees is higher due to tree pruning and because of lower tree competition, as the distance between individual trees is bigger.

It should be noted that the analysis of growth and development of urban plantations is limited due to the lack of empirical data (Rahman et al. 2017, 2019). Methodological problems become more urgent since there is a need for comprehensive studies to reveal the factors affecting woody species growing in urban environments (Rahman et al. 2017). The assessment of the regularities of growth and development of small-leaved linden plantations in the urban environment allows to estimate the plantations' silvicultural and taxation parameters to a greater extent. The sample size is not representative for the whole set of features. 
Table 2. Results of chemical analysis of separate and composite soil samples.

\begin{tabular}{|c|c|c|c|c|c|c|c|c|c|c|c|c|}
\hline \multirow{2}{*}{$\begin{array}{l}\text { Soil pit number, } \\
\text { sample depth } \\
\text { (cm) }\end{array}$} & \multirow{2}{*}{$\begin{array}{c}\text { Humus } \\
(\%)\end{array}$} & \multicolumn{2}{|c|}{$\mathrm{pH}$} & $\begin{array}{l}\text { Hydrologic } \\
\text { acidity }\end{array}$ & $\mathrm{Ca}$ & $\mathrm{Mg}$ & $\mathrm{Ca}+\mathrm{Mg}$ & $\mathrm{P}_{2} \mathrm{O}$ & $\mathrm{K}_{2} \mathrm{O}$ & \multirow{2}{*}{$\mathrm{N}-\mathrm{NO}_{3}$} & \multirow{2}{*}{$\mathrm{N}-\mathrm{NH}_{4}$} & \multirow{2}{*}{$\begin{array}{l}\text { Degree of } \\
\text { saturation }\end{array}$} \\
\hline & & Water & Salt & \multicolumn{4}{|c|}{ (mg.eq·100g.soil-1) } & \multicolumn{2}{|c|}{$\begin{array}{l}\text { (mg.100g. } \\
\text { soil }^{-1} \text { ) }\end{array}$} & & & \\
\hline \multicolumn{13}{|c|}{ Soil pit No.1 Prospect Oktyabrya avenue (Halle District bus stop - Ufa department store bus stop) } \\
\hline $0-30$ & 4.4 & 4 & 6.70 & 0.76 & 22.5 & 3.5 & 26.0 & 25.8 & 21.0 & 3.5 & 15.1 & 97.15 \\
\hline $30-40$ & 4.0 & 4 & 6.12 & 1.53 & 24.3 & 3.8 & 28.1 & 5.5 & 9.0 & 2.75 & 11.0 & 94.83 \\
\hline $40-60$ & 1.9 & C & 5.77 & 1.56 & 28.3 & 3.3 & 31.6 & 5.3 & 11.6 & 1.51 & 5.1 & 95.29 \\
\hline $60-80$ & 1.5 & C & 5.68 & 1.56 & 27.8 & 6.5 & 34.3 & 8.3 & 11.6 & 1.35 & 8.0 & 95.64 \\
\hline \multicolumn{13}{|c|}{ Soil pit No.2 Prospect Oktyabrya Avenue (Ufa Department store bus stop - Sportivnaia bus stop) } \\
\hline $0-20$ & 3.8 & 4 & 6.45 & 1.18 & 24.5 & 6.5 & 31.0 & 11.0 & 16.0 & 28.2 & 15.5 & 96.33 \\
\hline $20-40$ & 3.7 & 4 & 6.11 & 1.6 & 25.2 & 5.0 & 30.0 & 7.1 & 9.5 & 8.5 & 7.5 & 94.93 \\
\hline $40-65$ & 3.5 & C & 5.98 & 1.78 & 23.3 & 4.5 & 27.8 & 13.1 & 12.2 & 8.5 & 11.3 & 93.98 \\
\hline $66-80$ & 3.3 & C & 5.61 & 2.62 & 22.8 & 4.8 & 27.6 & 9.8 & 11.3 & 5.6 & 7.5 & 91.33 \\
\hline $81-100$ & 1.9 & C & 5.50 & 2.31 & 27.8 & 4.3 & 29.1 & 6.1 & 12.5 & 3.5 & 4.5 & 92.6 \\
\hline \multicolumn{13}{|c|}{ Soil pit No.3 Prospect Oktyabrya Avenue (Circus bus stop - Railway Hospital bus stop) } \\
\hline $0-20$ & 3.9 & 4 & 6.93 & 0.73 & 26.3 & 5.5 & 31.8 & 5.8 & 13.5 & 20.0 & 11.5 & 97.77 \\
\hline $31-40$ & 2.6 & 4 & 6.99 & 0.54 & 27.3 & 4.8 & 32.1 & 3.4 & 9.0 & 9.8 & 4.5 & 98.34 \\
\hline $41-65$ & 1.8 & 4 & 6.92 & 0.6 & 35.0 & 5.0 & 40.0 & 13.0 & 10.0 & 4.6 & 3.5 & 98.55 \\
\hline $66-102$ & 1.7 & 4 & 7.02 & 0.47 & 31.0 & 3.5 & 34.5 & 2.2 & 8.5 & 3.5 & 3.5 & 97.22 \\
\hline \multicolumn{13}{|c|}{ Soil pit No.4 G. M. Rutto Forest Park (Test 1) } \\
\hline $0-37$ & 3.2 & 4 & 6.22 & 1.46 & 31.3 & 4.8 & 36.1 & 4.6 & 16.5 & 11.2 & 10.0 & 96.11 \\
\hline $37-45$ & 2.7 & C & 5.69 & 2.02 & 35.8 & 5.5 & 41.3 & 3.6 & 15.6 & 7.4 & 5.5 & 95.33 \\
\hline $54-64$ & 2.5 & C & 5.84 & 1.6 & 37.5 & 4.8 & 42.3 & 16.7 & 17.2 & 5.8 & 8.0 & 96.35 \\
\hline $72-82$ & 1.5 & 4 & 6.98 & 0.63 & 33.3 & 3.8 & 37.1 & 2.7 & 11.0 & 8.0 & 3.5 & 98.33 \\
\hline $87-90$ & 0.9 & 4 & 7.15 & 0.44 & 23.8 & 2.8 & 26.6 & 1.3 & 9.0 & 7.1 & 3.5 & 98.37 \\
\hline $90-100$ & 0.6 & 4 & 7.25 & 0.36 & 16.8 & 2.3 & 19.1 & 1.9 & 6.5 & 4.1 & 1.5 & 98.15 \\
\hline \multicolumn{13}{|c|}{ Soil pit No.5. G. M. Rutto Forest Park (Test 1) } \\
\hline $0-25$ & 5.0 & C & 6.02 & 2.11 & 23.8 & 5.5 & 29.3 & 2.7 & 28.0 & 6.3 & 19.0 & 95.87 \\
\hline $25-40$ & 3.0 & 4 & 5.41 & 2.92 & 23.0 & 6.0 & 29.0 & 1.2 & 16.8 & 4.0 & 8.5 & 94.21 \\
\hline $40-60$ & 3.2 & 4 & 5.12 & 3.4 & 24.8 & 5.8 & 30.6 & 0.8 & 16.2 & 2.24 & 9.5 & 98.12 \\
\hline $60-70$ & 2.0 & $\mathrm{~N}$ & 4.55 & 5.37 & 26.3 & 6.8 & 33.1 & 0.4 & 15.0 & 1.05 & 9.0 & 93.4 \\
\hline $81-100$ & 1.9 & C & 4.17 & 5.48 & 29.0 & 7.3 & 36.3 & 0.4 & 14.6 & 0.96 & 5.5 & 94.79 \\
\hline
\end{tabular}

\section{CONCLUSIONS}

In this study the growth and development of smallleaved linden plantations in the urban environment were assessed at the example of the city of Ufa in the Republic of Bashkortostan. Based on the measurements, the analysis of linden silvicultural indicators was conducted. Sampling helped to make quantitative and percentage diameter distribution table. Statistical stand indicators were calculated. Based on this analysis, the following conclusions were made:

- artificially created alleys where Tilia cordata Mill. trees grow are better looked after, tree crowns there are more strongly developed, creating a shadow sometimes 8-10 meters wide (the average crown projection is $7 \mathrm{~m}$ ). Since alley plantings have repeatedly been pruned, trees in this area are characterized by a large increase in diameter and strong height growth stagnation. The average plant diameter is $34.1 \pm 0.02$ $\mathrm{cm}$, and the average height is $14 \pm 0.04 \mathrm{~m}$. Differences in diameter growth $\left(\mathrm{t}_{\text {fact }}=-0.07 \leq \mathrm{t}_{\text {theor }}=1.96\right)$ and height $\left(t_{\text {fact }}=0.02 \leq t_{\text {theor }}=1.96\right)$ were statistically insignificant;

- the studied even-aged linden trees showed a sharp difference in size and shape in comparison with other plantings. A tree growing in an open area (e.g. in the alley alongside Prospekt Oktyabrya Avenue) is of 
small height, has a spherical crown, thick and fissured bark, and thick boughs all over its tapered trunk. A forest tree (e.g. growing in the G. M. Rutto Park) has a full-boled, non-tapered trunk and a pyramid shaped crown;

- in the studied urbanized soils, the content of a fine granular structure in $0-30 \mathrm{~cm}$ of the soil layer under the canopy of linden alley plantings of 70 years of age is $71.27 \%-76.47 \%$, which determines their safety during repeated treatments and after artificial and natural moisture. Soils in the G. M. Rutto Park within $A_{0}-A_{1}$ horizon contain only $33.17 \%-37.30 \%$ of aggregates of fine granular structure. This suggests that the soils there are waterlogged, and that their air-heat balance is broken.

The results of this research allow to offer the following recommendations: the application of $100-120 \mathrm{~kg} \cdot \mathrm{ha}^{-1}$ of phosphoric and potassium fertilizers, since supply with these components is low, which will reduce the negative impact of pollution and strengthen the activity of microorganisms; creating alley plantings of small-leaved linden along the streets of the city of Ufa, increasing the number of rows to 2-3 and leaving a bigger distance between trees (at least $4 \mathrm{~m}$ ); care for the existing green plantings, including topiary, sanitary and renovation pruning.

\section{Author Contributions}

MM, RS1 conceived and designed the research; GO and RS2 carried out the field measurements; EK performed laboratory analysis; RS1 and GO processed the data and performed the statistical analysis; EK helped to draft the manuscript; MM and RS2 wrote the manuscript. Note: RS1 - Rida Sultanova, RS2 - Regina Sazgutdinova.

\section{Funding}

This research received no external funding.

\section{Conflicts of Interest}

The authors declare no conflict of interest.

\section{REFERENCES}

Bayer D, Reischl A, Rötzer T, Pretzsch H, 2018. Structural response of black locust (Robinia pseudoacacia L.) and small-leaved lime (Tilia cordata Mill.) to varying urban environments analyzed by terrestrial laser scanning: Implications for ecological functions and services. Urban For Urban Green 35: 129-138. https://doi. org/10.1016/i.ufug.2018.08.011.

Bijker RA, Sijtsma FJ, 2017. A portfolio of natural places: Using a participatory GIS tool to compare the appreciation and use of green spaces inside and outside urban areas by urban residents. Landscape Urban Plan 158: 155-165. https://doi. org/10.1016/j.landurbplan.2016.10.004.

Chopikashvili LV, Mamieva EB, Kornoukhov II, Kalabekov AL, 2014. Change of phenotypic features of small-leaved Linden in urban environment. News Gorsk State Agrar Univ 54(4): 402-406.

Field Studies of The Soil, 1984. The procedure and methods of work, the main requirements for the results: 56-81-84. AllUnion Standard of 12.10.1984. State forestry of the USSR, 17. Available online: https://znaytovar.ru/gost/2/OST_568184_ Polevye_issledovani.html (29 June 2019).

Forest Management Instruction, 2018. Approved by the order of the Ministry of Natural Resources of Russia of 29.03.2018 No. 122. EBD ConsultantPlus.

Glibovitskaia N, 2014. The functional status of small-leaved Linden (Tilia cordata Mill.) in urban growth. J Sci Public Postgrad Doct Stud 6: 214-216.

Gost R 56157-2014, 2016. Soil State All-Union Standard Methods (methods) of analysis of soil samples composition and properties. General requirements for the development. Available online: http://docs.cntd.ru/document/1200113844 (29 June 2019).

Gost R 58003-2017, 2018. Forest management and forest use. Certification requirements. Available online: http://docs.cntd. ru/document/1200157802 (29 June 2019).

Kabisch N, Haase D, 2014. Green justice or just green? Provision of urban green spaces in Berlin, Germany. Landscape Urban Plan 122: 129-139. https://doi.org/10.1016/i. landurbplan.2013.11.016.
Kabisch N, Strohbach M, Haase D, Kronenberg J, 2016. Urban green space availability in European cities. Ecol Indic 70: 586596. https://doi.org/10.1016/j.ecolind.2016.02.029.

Konashova SI, Sultanova RR, Khairetdinov AF, Gabdrakhimov KM, Konovalov VF, Rakhmatullin ZZ, Isianiulova RR, Nasirova ER, Gubaidullin AF, Muftakhova SI, 2018. Forestry and ecological aspects of the broad-left forest formation. J Eng Appl Sci 13(S11): 8789-8795. https://doi.org/10.36478/ jeasci.2018.8789.8795.

Margaritis E, Kang J, 2017. Relationship between green spacerelated morphology and noise pollution. Ecol Indic 72: 921933. https://doi.org/10.1016/j.ecolind.2016.09.032.

Moser A, Rötzer T, Pauleit S, Pretzsch H, 2015. Structure and ecosystem services of small-leaved lime (Tilia cordata Mill.) and black locust (Robinia pseudoacacia L.) in urban environments. Urban For Urban Green 14(4): 1110-1121. https://doi.org/10.1016/j.ufug.2015.10.005.

Moser A, Rahman MA, Pretzsch H, Pauleit S, Rötzer T, 2017. Interand intraannual growth patterns of urban small-leaved lime (Tilia cordata Mill.) at two public squares with contrasting microclimatic conditions. Int J Biometeorol 61(6): 1095-1107. https://doi.org/10.1007/s00484-016-1290-0.

Moser-Reischl A, Rahman MA, Pauleit S, Pretzsch H, Rötzer T, 2019. Growth patterns and effects of urban micro-climate on two physiologically contrasting urban tree species. Landscape Urban Plan 183: 88-99. https://doi.org/10.1016/i. landurbplan.2018.11.004.

Mudarisov SG, Gabitov II, Lobachevsky YP, Mazitov NK, Rakhimov RS, Khamaletdinov RR, Rakhimov RR, Farkhutdinov IM, Mukhamedtinov AM, Gareev RT, 2019. Modeling the technological process of tillage. Soil Till Res 190: 70-77. https://doi.org/10.1016/i.still.2018.12.004.

Nature Protection, 2008. Soils. List of indicators of suitability of the broken fertile soil layer for earth mulching: 17.4.0283. State All-Union Standard of 01.01.1984. Moscow. STANDARTINFORM, 4. Available online: https://allgosts. ru/13/080/gost_17.4.2.02-83 (29 June 2019). 
Rahman MA, Moser A, Rötzer T, Pauleit S, 2017. Within canopy temperature differences and cooling ability of Tilia cordata trees grown in urban conditions. Build Environ 114: 118-128. https://doi.org/10.1016/i.buildenv.2016.12.013.

Rahman MA, Moser A, Anderson M, Zhang C, Rötzer T, Pauleit $S$, 2019. Comparing the infiltration potentials of soils beneath the canopies of two contrasting urban tree species. Urban For Urban Gree 38: 22-32. https://doi.org/10.1016/j. ufug.2018.11.002.

Strohbach MW, Haase D, 2012. Above-ground carbon storage by urban trees in Leipzig, Germany: analysis of patterns in a European city. Landscape Urban Plan 104(1): 95-104. https:// doi.org/10.1016/j.landurbplan.2011.10.001.

Sultanova RR, Gabdrahimov KM, Khayretdinov AF, Konashova SI, Konovalov VF, Blonskaya LN, Sabirzyanov IG, Martynova MV, Isyanyulova RR, Gabdelkhakov AK, 2018. Evaluation of ecological potential of forests. J Eng Appl Sci 13(S8): 65906596. https://doi.org/10.3923/jeasci.2018.6590.6596.

Takács Á, Kiss M, Hof A, Tanács E, Gulyás Á, Kántor N, 2016. Microclimate modification by urban shade trees-an integrated approach to aid ecosystem service-based decision-making. Procedia Environ Sci 32: 97-109. https://doi.org/10.1016/i. proenv.2016.03.015.

Teplaya GA, 2013. Heavy metals as a factor of environmental pollution: a review. Astrakhan Proc Ecol Edu 23(1): 182.

Trammell TL, Schneid BP, Carreiro MM, 2011. Forest soils adjacent to urban interstates: soil physical and chemical properties, heavy metals, disturbance legacies, and relationships with woody vegetation. Urban Ecosyst 14(4): 525-552. https://doi. org/10.1007/s11252-011-0194-3.
Urošević MA, Jovanović G, Stević N, Deljanin I, Nikolić M, Tomašević $M$, Samson R, 2019. Leaves of common urban tree species (Aesculus hippocastanum, Acer platanoides, Betula pendula and Tilia cordata) as a measure of particle and particle-bound pollution: a 4-year study. Air Qual Atmos Health 12(9): 1081-1090. https://doi.org/10.1007/s11869019-00724-6.

Xu C, Haase D, Pauleit S, 2018. The impact of different urban dynamics on green space availability: A multiple scenario modeling approach for the region of Munich, Germany. Ecol Indic 93: 1-12. https://doi.org/10.1016/j.ecolind.2018.04.058.

Zhang C, Stratopoulos LMF, Pretzsch H, Rötzer T, 2019. How Do Tilia cordata Greenspire Trees Cope with Drought Stress Regarding Their Biomass Allocation and Ecosystem Services? Forests 10(8): 676. https://doi.org/10.3390/f10080676.

Ziiatdinova KZ, Urazgildin RV, Denisova AV, 2012. Accumulation of heavy metals in the leaves of the main forest growers of the Urals on the example of the Ufa industrial center. Proceedings of the XIX "Lomonosov" International Youth Scientific conference of students, postgraduates and 135 young scientists.

Zölch T, Henze L, Keilholz P, Pauleit S, 2017. Regulating urban surface runoff through nature-based solutions-An assessment at the micro-scale. Environ Res 157: 135-144. https://doi. org/10.1016/i.envres.2017.05.023. 